\title{
The effect of cultured autologous oral mucosal epithelial cells on ocular surface reconstruction
}

\author{
Minghong Gao, Yingxin Chen, Fengying Zhai, Zhiling Liu, Qiming Liu, Ziyue Wang
}

The General Hospital of Northern Theater Command, Shenyang, China

Submitted: 6 November 2019; Accepted: 20 December 2019

Online publication: 25 March 2021

Arch Med Sci

DOI: https://doi.org/10.5114/aoms/115576

Copyright @ 2022 Termedia \& Banach

\begin{abstract}
Introduction: Oral epithelial cells were recently shown to be able to differentiate into corneal epithelium, and the efficacy of cultured autologous oral mucosal epithelial cells (CAOMEC) has been suggested by the presence of epithelium replacement. Therefore, the aim of this study was to evaluate the treatment outcome in limbal stem cell deficiency (LSCD) by adding CAOMEC to regular amniotic membrane (AM) treatment.

Material and methods: Eyes with LSCD were randomized to two groups to undergo either autologous oral mucosal epithelial cell sheet (CAOMECS) combined with AM transplantation (A group) or AM transplantation alone (B group). Clinical outcome measures were corneal epithelium healing, best corrected visual acuity, symblepharon, corneal transparency, corneal neovascularization and ocular surface inflammation.

Results: The normal corneal epithelialization rate in group A (73.33\%) was higher than that in group B $(35.48 \%)$, and the average healing time was shorter $(3.45 \pm 2.12$ weeks vs. $4.64 \pm 1.63$ weeks). The symblepharon in the above two groups was improved in the first 3 months after surgery, but after 6 months, part of the B group had recurrence. In improving corneal transparency, group A has obvious advantages. Corneal neovascularization (CNV) was improved to some extent in the first 3 months after surgery, but group A $(1.47 \pm 0.64)$ was better than group B $(1.94 \pm 0.85)$ after 6 months. Both groups can improve the inflammatory state to some extent.

Conclusions: The transplantation of CAOMECS offers a viable and safe alternative in the reconstruction of a stable ocular surface. The effect is better than that of traditional AM transplantation, mainly in promoting corneal epithelialization, improving ocular surface structure, and reducing fiber and vascular infiltration.
\end{abstract}

Key words: limbal stem cell deficiency, amniotic membrane, cultured autologous oral mucosal epithelial cell sheet, ocular surface reconstruction.

\section{Introduction}

Limbal stem cells (LSCS) are located in the basal cell layer of the limbal epithelium and have regenerative potential, being able to migrate from the limbal to the central cornea to renew the corneal epithelium [1]. Stevens-Johnson syndrome (SJS), thermal and chemical injury, and ocular cicatricial pemphigoid ocular surface diseases could cause corneal limbal stem cell deficiency (LSCD), leading to poor corneal epithelial integrity, corneal vascularization, conjunctivalization, and corneal fibrous ingrowth [2, 3].

The key to treatment is to reconstruct the corneal epithelium, maintain corneal transparency and normal ocular surface structure, and

\author{
Corresponding author: \\ Yingxin Chen \\ The General Hospital \\ of Northern Theater \\ Command \\ Shenyang, China \\ E-mail: chenyingxin88@yeah. \\ net
}


maintain good appearance and vision. Transplantation of autologous limbal epithelium has been a promising procedure for treating unilateral limbal stem cell deficiencies [4], but reconstruction of the ocular surface that has been affected bilaterally is a challenging problem. Transplantation of allogeneic limbal epithelium has a great risk of immune rejection, which requires long-term use of immunosuppressive agents, which not only has a low success rate, but also may cause infection and damage the liver and kidney functions $[5,6]$. In recent years, the discovery of multiple differentiation ability of embryonic stem cells (ESC) [7] and lateral differentiation function of adult stem cells (ASC) [8] has promoted the construction of multi-source tissue engineering corneal epithelium. However, due to the ethical and sociological problems of ESC, ASC have provided a broad prospect for regenerative medicine based on cell therapy.

Oral epithelial cells were recently shown to be able to differentiate into corneal epithelium, and autologous cultivated oral mucosal epithelial transplantation (COMET) has demonstrated promising outcomes [9]. The cultured autologous oral mucosal epithelial cell sheet (CAOMECS) is manufactured by using a novel temperature-responsive culture well and is harvested without proteolytic processing,

retaining cell-to-cell junctions as well as the deposited extracellular matrix of the basal membrane of the sheet. The efficacy of CAOMECS transplantation has been suggested by the presence of epithelium replacement, in nonclinical studies using rabbit LSCD models $[10,11]$. Research in this area has been developing for more than a decade; however, the methods used have varied widely and there have been few reports of accurate anal- yses of the risks and benefits of this research area. In this study, we applied substrate-free CAOMECS combined with amniotic membrane transplantation to treat LSCD, and compared the efficacy with simple amniotic membrane transplantation, hoping to provide a clinical basis for ocular surface reconstruction.

\section{Material and methods}

\section{Patients}

The research adhered to the Declaration of Helsinki. Written informed consent was obtained from all patients before entering the study, which was approved by our hospital. The inclusion criteria were: 1) patients with LSCD due to chemical/thermal burns (According to the Dua classification standard [12]); 2) age over 18 years, regardless of gender; 3) there is no serious abnormality in intraocular pressure and eyelids; 4) ultrasound biomicroscope (UBM) inspection angle is more than $1 / 4$ quadrant; 5) no retinal detachment was detected by B-ultrasound. The exclusion criteria were: 1) systemic infection; 2) corneal infection or severe oral tissue injury within 1 year; 3) non-LSCD-induced keratoconjunctivitis in patients; 4) malignant tumor, heart disease, cerebrovascular disease, etc.; 5) pregnant or lactating patients.

A total of 44 patients (46 eyes) with severe LSCD were collected in this study, and were divided into two groups according to local conditions of oral mucosa and patients' intention. 15 patients (15 eyes) in group A received CAOMECS combined with amniotic membrane transplantation (AMT), and 29 patients (31 eyes) in group B only received AMT. All the candidates were male and in a stable condition. The basic preoperative information is shown in Table I.

Table I. Preoperative basic information

\begin{tabular}{|lcccc|}
\hline Parameter & $\begin{array}{c}\text { CAOMECS transplantation } \\
(n=15)\end{array}$ & $\begin{array}{c}\text { AM transplantation } \\
(n=31)\end{array}$ & $T / Z / \chi^{2}$ & $P$-value \\
\hline Age [years] & $43.1 \pm 13.3$ & $43.9 \pm 11.5$ & -0.203 & 0.840 \\
\hline LSCD severity & $5.27 \pm 0.80$ & $4.94 \pm 0.96$ & 0.348 & 0.804 \\
\hline \begin{tabular}{l} 
Causes: \\
\hline Acid burn
\end{tabular} & 3 & 3 & 1.197 & 0.599 \\
\hline Alkali burn & 4 & 8 & & \\
\hline Thermal burns & 8 & 20 & & \\
\hline Abnormal eyelid & $1.73 \pm 0.70(0-3)^{*}$ & $1.42 \pm 0.96(0-3)$ & 3.649 & 0.297 \\
\hline Symblepharon & $1.87 \pm 0.83(0-3)$ & $1.74 \pm 1.06(0-3)$ & 1.790 & 0.721 \\
\hline Inflammation & $1.00 \pm 0.54(0-2)$ & $1.16 \pm 0.78(0-3)$ & 2.648 & 0.452 \\
\hline Corneal transparency & $2.40 \pm 0.91(0-3)$ & $2.13 \pm 0.99(0-3)$ & 1.907 & 0.68 \\
\hline CNV & $2.80 \pm 0.41(2-3)$ & $2.26 \pm 0.77(0-3)$ & 5.660 & 0.079 \\
\hline Preoperative BCVA (BCVA LogMAR) & $2.85 \pm 1.03(0.4-4.0)$ & $2.60 \pm 1.39(0.1-5.0)$ & -0.546 & 0.585 \\
\hline AM - amniotic membrane, CAOMECS - cultured autologous oral mucosal epithelial cell sheet, LSCD - limbal stem cell deficiency, \\
CNV - corneal neovascularization, BCVA - best corrected visual acuity. & & &
\end{tabular}




\section{Cultivation of autologous oral mucosal epithelial cells}

A $10 \times 10 \mathrm{~mm}$ oral mucosa biopsy was excised from the cheek for epithelial cell culture in DMEM. Then the mucosal epithelium was digested in $0.25 \%$ trypsin- EDTA for $10 \mathrm{~min}$ at $37^{\circ} \mathrm{C}$. When the confluence reached $100 \%$, cells were incubated with dispase at $37^{\circ} \mathrm{C}$ for $8 \mathrm{~min}$. Before grafting, the sheet was detached by reducing the temperature to $20^{\circ} \mathrm{C}$ and transferred to a PVDF ring. The biological $A M$ was flattened after rehydration, and the oral mucosal epithelial cells were transferred with forceps to make them completely adhered to the amniotic membrane, and the complex was transferred to nitrocellulose, reserved at $4^{\circ} \mathrm{C}$. The cultivation process is shown in Figure 1.

\section{Immunofluorescence analysis}

After fixation with $4 \%$ paraformaldehyde, cells were permeabilized with methanol, and blocked with $5 \%$ BSA in PBS for 20 min. Then the specimens were incubated in a humidified chamber with primary antibodies directed against P63 and $\beta$-integrin. After incubation, the cells were washed with PBS followed by secondary antibody (1: 200). After the nuclei were counterstained with DAPI, the samples were observed under a fluorescence microscope (Olympus, Japan).

\section{Hematoxylin and eosin staining}

The specimens were deparaffinized in xylene and rehydrated in a series of alcohol solutions. After a brief wash in distilled water, the specimens were stained with Harris hematoxylin solution for $5 \mathrm{~min}$, washed in tap water and counterstained in eosin-phloxine solution for $2 \mathrm{~min}$.

\section{Colony-forming unit-fibroblasts 121 (CFU-F) assay}

The epithelial cells were seeded into a $6-\mathrm{cm}$ cell culture dish (Falcon). After incubation at $37^{\circ} \mathrm{C}$ for 10 days, the cells were washed with PBS and stained with $0.5 \%$ Crystal Violet in methanol for 5 min. Cells were washed with PBS twice and visible colonies were counted. To isolate colonies, unstained colonies were recovered using cloning cylinders and trypsin EDTA.

\section{Surgical procedures}

After $0.04 \%$ mitomycin C treatment for 3 months was followed by thorough washing with saline solution, then the rehydrated AM (JiXi RuiJi BioTechnology Co., Ltd, Jiangxi, China), and the CAOMECS and AM complex were grafted onto the cornea and bare sclera and were sutured at the conjunctival edge with interrupted polyglactin 910
(Coated Vicryl; Ethicon, Tokyo, Japan) sutures. After surgery, topical antibiotics and corticosteroids were initially applied four times a day and then three times a day. $0.3 \%$ preservative-free hyaluronic acid (Hyalein-Mini; Santen Pharmaceutical Co), and $20 \%$ autologous serum eye drops were used for epithelial management. After 1 month, the drug was gradually reduced according to the eye condition, and sodium hyaluronate was administered for half a year.

\section{Clinical evaluation}

Clinical success was defined as a stable ocular surface including: 1) no corneal epithelial defect; 2) no corneal pupillary vascularization and fibrovascular infiltration; 3) no or mild conjunctival inflammation; 4) no sacral adhesion in the pupil area. Clinical failure was defined as follows: 1) recurrent or persistent corneal epithelial defects, which are resistant to all treatments; 2) CNV or fibrovascular tissue infiltrates into the pupil area; 3 ) recurrence of symblepharon covers the pupil area.

The primary endpoint for efficacy was the comparison of corneal epithelial healing rate and healing time (Luciferin sodium staining was performed for the first time since the amniotic suture was removed $2 \mathrm{w}$ after surgery) after CAOMECS combined with AM transplantation and AM transplantation alone. The secondary endpoints were:

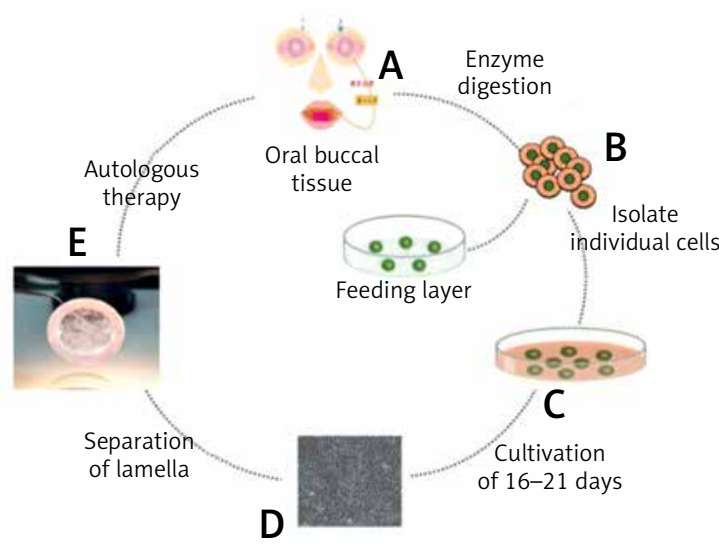

Figure 1. The basic process of cultured oral mucosa epithelial cells in vitro. Under local anesthesia, buccal mucosa tissue of about $10 \mathrm{~mm} \times 10 \mathrm{~mm}$ in size was cut into the patient's mouth (A). The buccal mucosa is enzymatically treated as a single cell (B). The separated cells were placed in a 6-well plate, cultured at $37^{\circ} \mathrm{C}$ with $5 \%$ carbon dioxide (C). Multi-layered cell colonies formed after 16-21 days of culture; the cells are flat and irregular polygons, and there are round nuclei in the center. The cells are closely connected to each other to form a single-layer membrane, which grows like a paving stone and closely depends on it (D). A complete oral mucosal epithelial cell sheet was obtained by cooling, and a nitrocellulose membrane was used as a graft ring $(\mathrm{E})$ 
1) visual changes in patients; 2) corneal transparency improvement [13]; 3) patient CNV status [14]; 4) improvement of symblepharon [15]); 5) ocular surface inflammation.

\section{Follow-up}

The routine follow-up time was 2 weeks, 1 month, 3 months and 6 months after surgery and the follow-up time could be adjusted according to the postoperative eye conditions of the patients.

\section{Statistical analysis}

Statistical analyses were performed with SPSS 25.0 (IBM Corp., USA). Before the surgery, Student's t test was used for preoperative age comparison. The chi-square test was used for the comparison of etiology, the success rate of different treatment methods and the epithelialization rate. A nonparametric test was used to detect preoperative visual acuity, eyelid abnormalities, degree of symblepharon, corneal transparency,
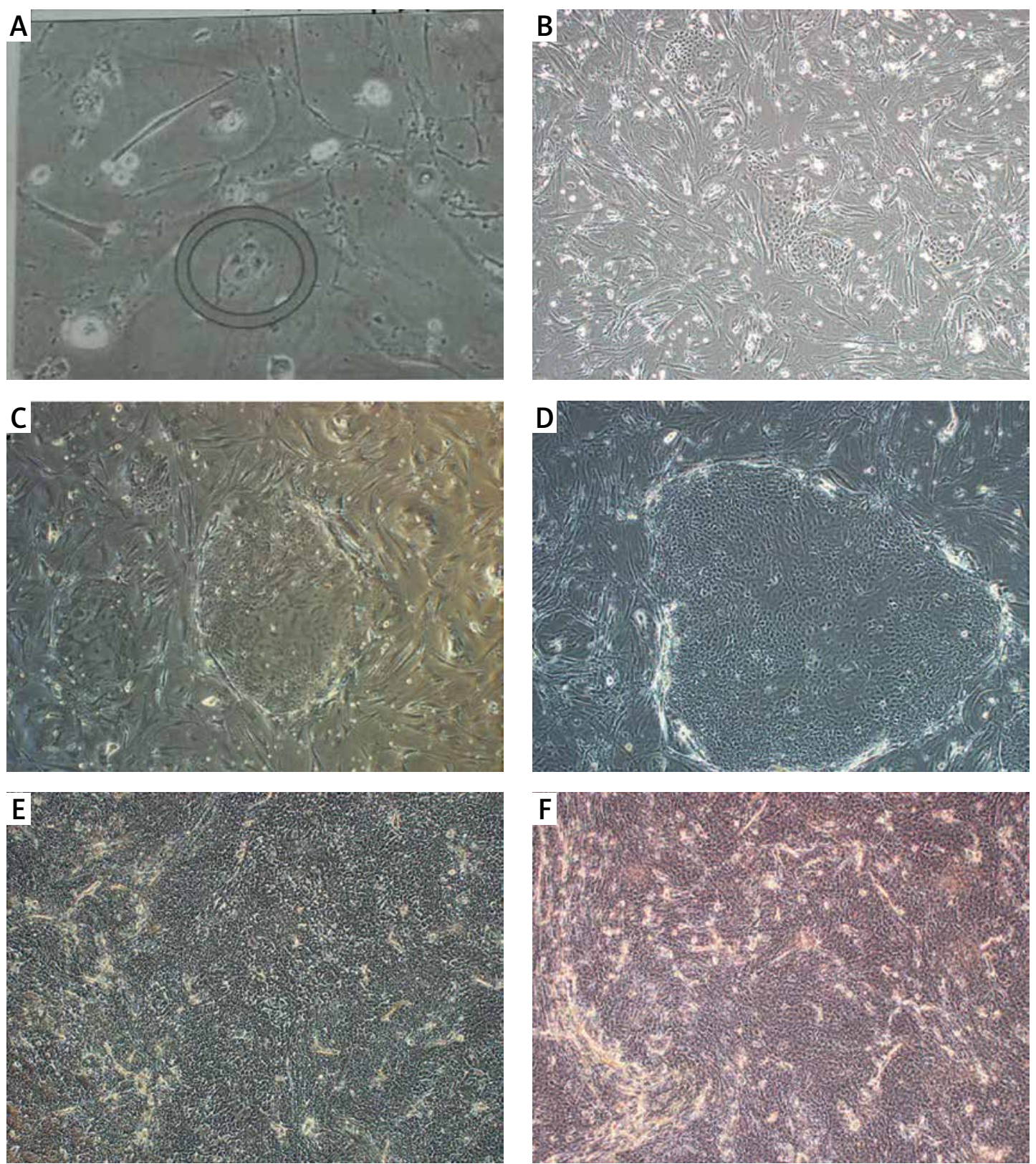

Figure 2. The growth of autologous oral cells cultured in vitro. A - The cells were adherent with a low adherent rate, good adherent cell status and no pollution ( 3 days). B - The cells adhered to the wall and an obvious clonal cluster appeared (6-8 days). C - After the cells adhered to the cells, and the clonal colony-proliferating cells were uniform, the cells were non-contaminated, and the cell confluence was about 30\% (8-10 days). D - The cells proliferated rapidly and large cells appeared in the center of the clone group (10-12 days). E - The cells adhered to the cells, and there were large cells in individual parts of the cells, and the cells were free from contamination (12-14 days). $\mathbf{F}$ - the cells grew in a paving stone state (17-20 days) 
degree of corneal neovascularization and degree of inflammation. After the surgery, Wilcoxon's rank sum test was used for the comparison of various parameters. A $P$ value of $<0.05$ was considered statistically significant.

\section{Results}

\section{Changes in oral mucosal epithelial cell} culture

The growth of autologous oral cells cultured in vitro is shown in Figure 2. After 3 days of culture, the cells were adherent with a low adherent rate, good adherent cell status and no pollution (Figure 2 A). After 6-8 days of culture, the cells adhered to the wall and an obvious clonal cluster appeared (Figure 2 B). After 8-10 days, the cells adhered to the cells, and the clonal colony-proliferating cells were uniform, the cells were non-contaminated, and the cell confluence was about 30\% (Figure 2 C). After 10-12 days, the cells proliferated rapidly and large cells appeared in the center of the clone group (Figure 2 D). After 12-14 days, the cells adhered to the cells, and there were large cells in individual parts of the cells, and the cells were free from contamination. Cell confluence was about 95\% (Figure $2 \mathrm{E}$ ). After 17-20 days, the cells grew in a paving stone state (Figure $2 \mathrm{~F}$ ).

\section{Characterization of tissue-engineered epithelial cell sheets}

Strong immunogenicity of $\beta 1$-integrin and p63 was observed in immunofluorescence analysis (Figure $3 \mathrm{~A}, \mathrm{~B}$ ), and statistical analysis showed that the positive rate was more than $3 \%$. HE staining results showed that the cultured oral epithelial cells were very similar to the normal corneal tissue structure, which proved that the cell repair function was intact (Figure $3 \mathrm{C}$ ). CFU-F assay indicated that the colonies were uniformly colored, with neat edges, and grew in a round or oval shape (Figure $3 \mathrm{D}$ ). More specifically, clone formation rate was 3\%, indicating a strong ability of cell proliferation.
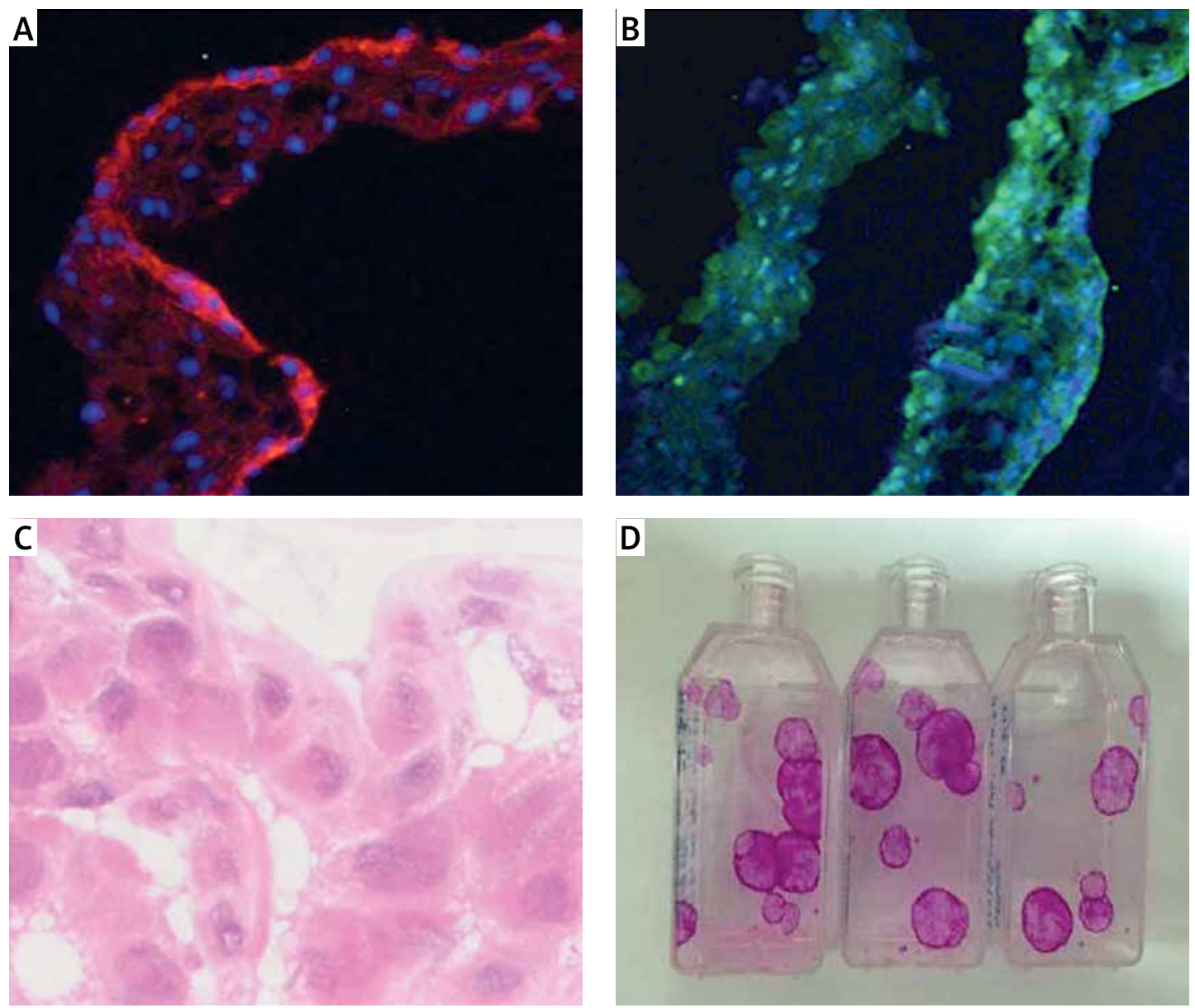

Figure 3. Characterization of tissue-engineered epithelial cell sheets. A - Strong immunogenicity of $\beta 1$-integrin was observed in immunofluorescence analysis. B - Strong immunogenicity of p63 was observed in immunofluorescence analysis. C - HE staining results showed that the cultured oral epithelial cells were very similar to the normal corneal tissue structure. D - CFU-F assay indicated that the colonies were uniformly colored, with neat edges, and grew in a round or oval shape 


\section{Corneal epithelial healing}

Eleven eyes (73.33\%) of group A and 11 eyes (35.48\%) of group B had normal corneal epithelialization. There was a statistically significant difference ( $p=0.02$ ) between the two groups. In the eyes with normal corneal epithelialization, the mean time of complete epithelial healing in group A and group B was $3.45 \pm 2.12$ weeks and $4.64 \pm 1.63$ weeks, with a significant difference between the two groups $(p=0.04)$.

\section{Visual outcomes}

In group $A$, the mean postoperative BCVA values (log MAR) at 2 weeks, 1 month, 3 months and 6 months were $2.39 \pm 0.75,2.27 \pm 1.03,2.27 \pm 0.82$ and $2.35 \pm 0.86$, respectively, which were statistically different from those before the operation $(p<0.05)$. In group $\mathrm{B}$, there was no statistically significant difference at each time point $(p=0.29$, $p=0.31, p=0.79$ and $p=0.86$ ). There was no significant difference between the two groups at any time after the surgery $(p=0.04, p=0.23, p=0.14$ and $p=0.25$; Table II).

\section{Symblepharon}

There was a statistically significant difference in the degree of symblepharon between preoperative and postoperative periods (postoperative 2 weeks, 1 month, 3 months and 6 months) in group A (all $p<0.05$ ) and Group B (all $p<0.05$ ). The intergroup comparison showed that only at 6 months after surgery was there a statistically significant difference between the two groups $(p=0.04$; Table III).

\section{Corneal transparency}

In group $A$, the differences in corneal transparency between preoperative and postoperative 2 weeks, 1 month, 3 months and 6 months were statistically significant (all $p<0.05$ ). However, in group B, only postoperative 2 weeks, 1 month and 3 months were significantly different from those before surgery $(p<0.05)$. Table IV shows the comparison of corneal transparency between the two groups during postoperative follow-up. The table shows that there were significant differences between the other 3 follow-up time points except for 1 month after surgery.

\section{Corneal neovascularization}

Compared with preoperative corneal neovascularization (CNV), there were statistically significant differences at postoperative 2 weeks, 1 month, 3 months and 6 months $(p<0.05)$ in group $A$, while in group $\mathrm{B}, p<0.05, p<0.05, p=0.003$ and $p=0.013$, respectively. Comparison between groups $A$ and $B$ showed that there were statistically significant differences between the two groups at 1 month and 6 months after surgery (Table V).

Table II. Comparison of postoperative BCVA between the two groups

\begin{tabular}{|lcccc|}
\hline Time [months] & CAOMECS group & AM group & Z-value & $P$-value \\
\hline 0.5 & $2.39 \pm 0.75(0.4-3.0)$ & $2.57 \pm 1.39(0.1-5.0)$ & -1.290 & 0.197 \\
\hline 1 & $2.27 \pm 1.03(0.4-3.0)$ & $2.63 \pm 1.43(0.1-5.0)$ & -1.187 & 0.235 \\
\hline 3 & $2.27 \pm 0.82(0.4-3.0)$ & $2.63 \pm 1.43(0.1-5.0)$ & -1.473 & 0.141 \\
\hline 6 & $2.35 \pm 0.86(0.4-3.0)$ & $2.64 \pm 1.43(0.1-5.0)$ & -1.160 & 0.246 \\
\hline
\end{tabular}

AM - amniotic membrane, CAOMECS - cultured autologous oral mucosal epithelial cell sheet.

Table III. Comparison of postoperative symblepharon between the two groups

\begin{tabular}{|lcccc|}
\hline Time [months] & CAOMECS group & AM group & Z-value & $P$-value \\
\hline 0.5 & $0.00 \pm 0.00(-)$ & $0.00 \pm 0.00(-)$ & - & - \\
\hline 1 & $0.00 \pm 0.00(-)$ & $0.13 \pm 3.41(0-1)$ & -1.440 & 0.150 \\
\hline 3 & $0.27 \pm 0.46(0-1)$ & $0.65 \pm 0.89(0-3)$ & -1.523 & 0.128 \\
\hline 6 & $0.33 \pm 0.49(0-1)$ & $1.16 \pm 1.07(0-3)$ & -2.110 & 0.035 \\
\hline
\end{tabular}

Table IV. Comparison of postoperative corneal transparency between the two groups

\begin{tabular}{|llccc|}
\hline Time [months] & CAOMECS group & AM group & Z-value & $P$-value \\
\hline 0.5 & $0.67 \pm 0.49(0-1)$ & $1.23 \pm 1.06(0-3)$ & -1.670 & 0.095 \\
\hline 1 & $0.87 \pm 0.74(0-2)$ & $1.42 \pm 1.12(0-3)$ & -1.550 & 0.121 \\
\hline 3 & $1.20 \pm 0.78(0-2)$ & $1.94 \pm 1.03(0-3)$ & -2.456 & 0.014 \\
\hline 6 & $1.33 \pm 0.74(0-2)$ & $2.03 \pm 0.88(0-3)$ & -2.472 & 0.013 \\
\hline
\end{tabular}

AM - amniotic membrane, CAOMECS - cultured autologous oral mucosal epithelial cell sheet. 
Table V. Comparison of postoperative CNV between the two groups

\begin{tabular}{|llccc|}
\hline Time [months] & CAOMECS group & AM group & $Z$-value & $P$-value \\
\hline 0.5 & $0.20 \pm 0.41(0-1)$ & $0.65 \pm 0.66(0-2)$ & -1.285 & 0.288 \\
\hline 1 & $0.87 \pm 0.74(0-2)$ & $1.29 \pm 0.90(0-3)$ & -1.481 & 0.139 \\
\hline 3 & $1.60 \pm 0.74(0-3)$ & $1.84 \pm 0.90(0-3)$ & -0.898 & 0.369 \\
\hline 6 & $1.47 \pm 0.64(1-3)$ & $1.94 \pm 0.85(0-3)$ & -2.078 & 0.038 \\
\hline
\end{tabular}

CNV - corneal neovascularization, AM - amniotic membrane, CAOMECS - cultured autologous oral mucosal epithelial cell sheet.

Table Vl. Comparison of postoperative inflammation between the two groups

\begin{tabular}{|lcccc|}
\hline Time [months] & CAOMECS group & AM group & $Z$-value & $P$-value \\
\hline 0.5 & $2.33 \pm 0.49(2-3)$ & $2.35 \pm 0.61(1-3)$ & -0.269 & 0.788 \\
\hline 1 & $1.47 \pm 0.52(1-2)$ & $1.52 \pm 0.72(0-3)$ & -0.273 & 0.785 \\
\hline 3 & $0.60 \pm 0.51(0-1)$ & $0.97 \pm 0.75(0-2)$ & -1.577 & 0.115 \\
\hline 6 & $0.40 \pm 0.51(0-1)$ & $0.55 \pm 0.62(0-2)$ & -0.681 & 0.496 \\
\hline
\end{tabular}

AM - amniotic membrane, CAOMECS - cultured autologous oral mucosal epithelial cell sheet.

\section{Inflammation}

In group $A$, there were statistically significant differences in the degree of inflammation between preoperative and postoperative levels at 2 weeks, 1 month, 3 months and 6 months, while in group $B$, there were statistically significant differences except for 3 months after surgery (Table VI).

Group A succeeded in 11 eyes (73.33\%), failed in 4 eyes (26.67\%), group B succeeded in 11 eyes (35.5\%), and failed in 20 eyes (64.5\%). The ocular surface conditions are shown in Figure 4 A and $B$ are the preoperative ocular conditions of the $A M$ group; C and D are corresponding postoperative ocular surface conditions. $C$ was the successful eye, with significant improvement in epithelial healing, symblepharon, neovascularization and corneal transparency. D was the failing eye, symblepharon recurred after operation, and the ocular surface was not significantly improved. E and $F$ are the preoperative ocular conditions of the CAOMECS group; $\mathrm{G}$ and $\mathrm{H}$ are corresponding postoperative ocular surface conditions. $G$ was the successful eye; corneal transparency, neovascularization and inflammatory state are significantly improved. F was the failure eye, and the ocular surface condition has not been improved (Figure 4).

\section{Discussion}

The treatment of ocular chemical/thermal burns has always been a challenge, and most patients with mild-to-moderate ocular burns have a stable ocular surface and visual function after treatment. Some patients with moderate and severe chemical/thermal burns have a poor prognosis and develop LSCD. Recently, many autologous tissue culture grafts have been studied to reconstruct the corneal limbus, among which oral mucosa epithelium is the most commonly used. In addition, oral mucosal epithelial grafts have been reported for the treatment of corneal ulcers [16]. Oral mucosal epithelial cells are in the lower stage of cell differentiation and cell renewal period, with short culture time, and can maintain long-term non-keratinization in vitro $[17,18]$, so they can be
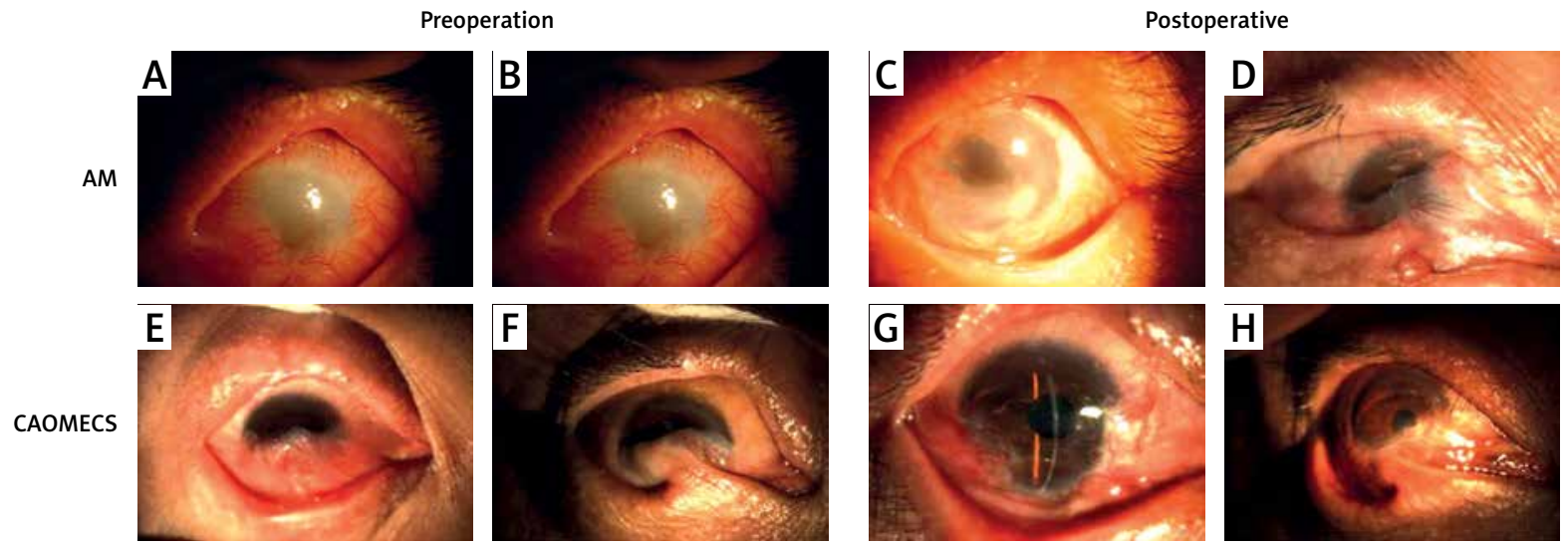

Figure 4. $\mathbf{A}$ and $\mathbf{B}$ are the preoperative ocular conditions of the AM group; $\mathbf{C}$ and $\mathbf{D}$ are corresponding postoperative ocular surface conditions. $\mathbf{E}$ and $\mathbf{F}$ are the preoperative ocular conditions of the CAOMECS group; $\mathbf{G}$ and $\mathbf{H}$ are corresponding postoperative ocular surface conditions 
an ideal substitute for corneal epithelium for ocular surface reconstruction.

In this study, a substrate-free temperature-sensitive medium was used, and the culture time was 2-3 weeks. The culture method was basically the same as in the previous study [19]. The difference from other culture methods lies in the absence of substrates and 3T3 feeder layers, and the use of autologous serum as a nutrient solution to avoid foreign pathogens or cancer cells. Studies have shown that the transplantation effect of substrate-free cell slices is significantly better than that of cultured cell slices on amniotic membrane, and the survival rate of grafts is significantly improved [20,21]. However, cell transplantation without substrates is challenging due to the lack of mechanical strength provided by various culture substrates. In this study, in addition to the separate CAOMECS, the successfully cultured CAOMECS was integrated with the amniotic membrane. On the one hand, it can increase the number of epithelial stem cells; on the other hand, it can integrate with amniotic membrane to facilitate transplantation and resist the shear force of surgical traction and postoperative blink and eye movement.

p63 is a marker of undifferentiated cells, and healthy limbus has strong expression of p63 in the basal layer of the epidermis and superficial epithelium [22]. In our study, staining and statistical analysis showed that the positive rate of p63 was more than $3 \%$, indicating that CAOMECS had corneal epithelioid characteristics. This is consistent with the previous research results of Utheim et al. [23]. In terms of promoting corneal epithelialization time, CAOMECS combined with AM transplantation is superior to AMT, but it is longer than other reported times [13]. The possible reason may be that the amniocentesis time is 2 weeks after surgery, and the staining is started at this time. It is also possible that the patients included in this study all had severe LSCD, which is caused by a different baseline. Symblepharon was improved in both groups, but some symblepharon recurred 3 months after surgery, and the recurrence rate was higher in the AM group. Our results are consistent with previous reports that the recurrence time of symblepharon after AMT is generally 3 months postoperatively, and the more severe the symblepharon is, the higher the recurrence rate is, and CAOMECS will reduce the recurrence of symblepharon [24].

Corneal neovascularization is a major complication of ocular chemical/heat burn, which results in transparency and loss of immune function [14]. Therefore, preventing and reversing CNV is very important to improve vision after burn. In our study, postoperative CNV was improved in both groups, but there were statistically significant differences at 1 month and 6 months. This may be because postoperative 2 weeks was the early stage, and CNV showed no significant change immediately, while 3 months after surgery, CNV in both groups showed a progressive state. These results were consistent with previous reports that CNV appeared in the first few months after surgery and reached a peak in 3-6 months [25]. The corneal transparency of the CAOMECS group was improved after the operation and basically stable 3 months later, which was consistent with a previous study [13]. In the AM group, corneal transparency improved in the first 3 months after surgery, but the corneal transparency after 6 months was not statistically different from the preoperative transparency, which may be related to the recurrence of symblepharon adhesion and the increase of conjunctival neovascularization. In the study, although corneal neovascularization and fibrosis were significantly improved after surgery, visual acuity was generally not significant, especially in the AMT group. It has been reported that the success rate after LSCD surgery may not be correlated with visual acuity [14]. In this study, the success rate after CAOMECS transplantation was $75 \%$, and in previous studies, the success rate was generally $70 \%$ to $79.3 \%[23,25]$. Severe eyelid abnormality and symblepharon were found in most of the failure group.

In conclusion, CAOMECS combined with AM transplantation for the treatment of severe chemical/thermal burns of the eyes can better reduce inflammation, promote corneal epithelialization, eliminate conjunctivalization, reduce fiber infiltration, and even improve vision compared to AMT alone. In addition, it provides a better environment for future cataract extraction or artificial corneal transplantation.

\section{Conflict of interests}

The authors declare no conflict of interest.

\section{References}

1. Kinoshita S, Adachi W, Sotozono C, Nishida K, Yokoi N, Quantock AJ, et al. Characteristics of the human ocular surface epithelium. Prog Retin Eye Res 2001; 20: 639-73.

2. Dua HS, Azuara-Blanco A. Limbal stem cells of the corneal epithelium. Surv Ophthalmol 2000; 44: 415-25.

3. Prabhasawat P. Corneal limbal stem cells. Siriraj Med J 2006; 58: 728-9.

4. Kenyon KR, Tseng SC. Limbal autograft transplantation for ocular surface disorders. Ophthalmology 1989; 96: 709-22; discussion 22-3.

5. Solomon A, Ellies P, Anderson DF, Touhami A, Grueterich $M$, Espana $E M$, et al. Long-term outcome of keratolimbal allograft with or without penetrating keratoplas- 
ty for total limbal stem cell deficiency. Ophthalmology 2002; 109: 1159-66.

6. Alfonso EC. Treatment of severe ocular-surface disorders with corneal epithelial stem cell transplantation. Arch Ophthalmol 2000; 118: 123-4.

7. Mikhailova A, Ilmarinen T, Ratnayake A, Petrovski G, Uusitalo $\mathrm{H}$, Skottman $\mathrm{H}$, et al. Human pluripotent stem cell-derived limbal epithelial stem cells on bioengineered matrices for corneal reconstruction. Exp Eye Res 2016; 146: 26-34.

8. Pietronave S, Prat M. Advances and applications of induced pluripotent stem cells. Can J Physiol Pharmacol 2012; 90: 317-25.

9. Sotozono C, Inatomi T, Nakamura T, Koizumi N, Yokoi N, Ueta $\mathrm{M}$, et al. Cultivated oral mucosal epithelial transplantation for persistent epithelial defect in severe ocular surface diseases with acute inflammatory activity. Acta Ophthalmol 2014; 92: e447-53.

10. Nishida K, Yamato M, Hayashida Y, Watanabe K, Maeda N, Watanabe $\mathrm{H}$, et al. Functional bioengineered corneal epithelial sheet grafts from corneal stem cells expanded ex vivo on a temperature-responsive cell culture surface. Transplantation 2004; 77: 379-85.

11. Hayashida Y, Nishida K, Yamato M, Watanabe K, Maeda $\mathrm{N}$, Watanabe $\mathrm{H}$, et al. Ocular surface reconstruction using autologous rabbit oral mucosal epithelial sheets fabricated ex vivo on a temperature-responsive culture surface. Invest Ophthalmol Vis Sci 2005; 46: 1632-9.

12. Dua HS, King AJ, Joseph A. A new classification of ocular surface burns. Br J Ophthalmol 2001; 85: 1379-83.

13. Prabhasawat P, Ekpo P, Uiprasertkul M, Chotikavanich S, Tesavibul N, Pornpanich K, et al. Long-term result of autologous cultivated oral mucosal epithelial transplantation for severe ocular surface disease. Cell Tissue Bank 2016; 17: 491-503.

14. Panda A, Jain M, Vanathi M, Velpandian T, Khokhar S, Dada T. Topical autologous platelet-rich plasma eyedrops for acute corneal chemical injury. Cornea 2012; 31: 989-93.

15. Kheirkhah A, Blanco G, Casas V, Hayashida Y, Raju VK, Tseng SC. Surgical strategies for fornix reconstruction based on symblepharon severity. Am J Ophthalmol 2008; 146: 266-75.

16. Shore JW, Foster CS, Westfall CT, Rubin PA. Results of buccal mucosal grafting for patients with medically controlled ocular cicatricial pemphigoid. Ophthalmology 1992; 99: 383-95.

17. Hata K, Kagami H, Ueda M, Torii S, Matsuyama M. The characteristics of cultured mucosal cell sheet as a material for grafting; comparison with cultured epidermal cell sheet. Ann Plast Surg 1995; 34: 530-8.

18. Ueda M, Hata K, Horie K, Torii S. The potential of oral mucosal cells for cultured epithelium: a preliminary report. Ann Plast Surg 1995; 35: 498-504.

19. Obokata H, Yamato M, Yang J, Nishida K, Tsuneda S, Okano T. Subcutaneous transplantation of autologous oral mucosal epithelial cell sheets fabricated on temperature-responsive culture dishes. J Biomed Mater Res A 2008; 86: 1088-96.

20. Hirayama M, Satake Y, Higa K, Yamaguchi T, Shimazaki J. Transplantation of cultivated oral mucosal epithelium prepared in fibrin-coated culture dishes. Invest Ophthalmol Vis Sci 2012; 53: 1602-9.

21. Sotozono C, Inatomi T, Nakamura T, Koizumi N, Yokoi N, Ueta $M$, et al. Visual improvement after cultivated oral mucosal epithelial transplantation. Ophthalmology 2013; 120: 193-200.
22. Chen P, Zhou Q, Wang J, Zhao X, Duan H, Wang Y, et al. Characterization of the corneal surface in limbal stem cell deficiency and after transplantation of cultured allogeneic limbal epithelial cells. Graefes Arch Clin Exp Ophthalmol 2016; 254: 1765-77.

23. Utheim TP, Utheim OA, Khan QE, Sehic A. Culture of oral mucosal epithelial cells for the purpose of treating limbal stem cell deficiency. J Funct Biomater 2016; 7: 5.

24. Kilic K, Konya D, Kurtkaya O, Sav A, Pamir MN, Kilic T. Inhibition of angiogenesis induced by cerebral arteriovenous malformations using gamma knife irradiation. J Neurosurg 2007; 106: 463-9.

25. Utheim TP. Concise review: transplantation of cultured oral mucosal epithelial cells for treating limbal stem cell deficiency-current status and future perspectives. Stem Cells 2015; 33: 1685-95. 
Minghong Gao, Yingxin Chen, Fengying Zhai, Zhiling Liu, Qiming Liu, Ziyue Wang 